\title{
Evaluation of Radiation Methods for Calculating the Water Requirement of Grass in Two Different Climates using REF-ET Software
}

\author{
Masoumeh Najafi $^{1 *}$, Mohammad Salarian ${ }^{1}$, Saeid Eslamian ${ }^{1}$, Kaveh Ostad-Ali-Askari ${ }^{2}$, Vijay P. \\ Singh $^{3}$, Nicolas R. Dalezios ${ }^{4}$

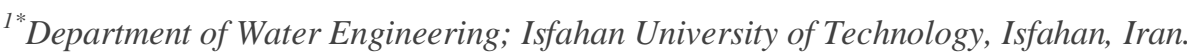 \\ ${ }^{2}$ Department of Civil Engineering, Isfahan (Khorasgan) Branch, Islamic Azad University, Isfahan, Iran. \\ ${ }^{3}$ Department of Biological and Agricultural Engineering \&Zachry Department of Civil Engineering, Texas A \\ and M University, 321 Scoates Hall, 2117 TAMU, College Station, Texas 77843-2117, U.S.A. \\ ${ }^{4}$ Laboratory of Hydrology, Department of Civil Engineering, University of Thessaly, Volos, Greece \& \\ Department of Natural Resources Development and Agricultural Engineering, Agricultural University of \\ Athens, Athens, Greece.
}

*Corresponding Author: Masoumeh Najafi, Department of Water Engineering; Isfahan University of Technology, Isfahan, Iran.

\begin{abstract}
Evapotranspiration plays a fundamental role in agricultural water management. Its calculation requires weather data, such as radiation, which are often not available and should be estimated indirectly. This study employed the Ref-ET software for estimating radiation for the period of 1970-2011 under two different climates of Rasht and Isfahan. Results showed that for Isfahan, the first method (minimum and maximum temperature difference) was satisfied with $K R S=0.17$, indicating good results. For Rasht, radiation was estimated using the third method $\left(K_{R S}\right)$ assuming $K_{R S}=0 / 44$, and the evapotranspiration relative to the values of evapotranspiration in the presence of data was acceptable. Also, results of evapotranspiration derived from the Turque equation in Isfahan and results of the Penman-Monteith FAO relation for Rasht were more acceptable.
\end{abstract}

Keywords: Radiation; Rapid Evaporation; REF-ET

\section{INTRODUCTION}

The supply of water needed for maximum crop growth, total water consumption, and the determination of capacity of canals and reservoirs constitute the important parts of an irrigation and drainage project. The Penman-Monteith method, approved by the FAO, is the standard for calculating the evapotranspiration of reference crop. (Gang et al. 2006). This method requires a large amount of climate data, but sometimes a number of meteorological parameters, such as radiation, temperature, and precipitation, are not available (Mayer \& Isomer 2002; Almoux et al., 2005). It may be noted that the sensitivity of evapotranspiration to meteorological parameters is not the same in different regions; hence it may be necessary to more precisely estimate some of the parameters. While estimating evapotranspiration by the Penman-Monteith FAO 56 model and the fuzzy inference system, An sari and Moradi (2011) found that solar radiation was the most effective parameter. SabziParvar et al. (2007) evaluated the sensitivity of the Penman-Monteith FAO-56, Jensen-Hayes, and Hargreaves models to weather parameters and found that evapotranspiration was most sensitive to solar radiation parameters and air temperature. On estimating evapotranspiration by the Penman-Monteith method for 64 stations from different climatic regions of China, Thomas (2000) found that solar radiation had the highest impact in the south, and wind speed, relative humidity, and maximum temperature were the main factors in the northeast, the center, and northwest of China.

Some of the weather parameters can be estimated and some measured. Erfanian and Babaii (2013) compared three models for estimating radiation, including hybrid models, modified Daneshyar and Sabbaghin a study on evapotranspiration in Tabriz, Iran, and found that the hybrid model had a higher accuracy than the two other models. Comparing hybrid and Angstrom-Prescott models at 14 stations in Japan, Yang et al. (2001) concluded that the hybrid model performed better than did the Angstrom- 
Prescott model. In another study on a number of U.S., Japan and Saudi stations, Yang et al. (2005) concluded that the hybrid model was able to accurately estimate solar radiation at daily and hourly scales than were the FAO and Angstrom -Precast models with global coefficients.

The objective of this study therefore was to identify the best method for estimating radiation with the Ref-ET software in two different climates of Rasht and Isfahan, Iran. To that end, minimum temperature, maximum temperature, minimum humidity, maximum moisture content, wind speed, and the sunshine hours were used.

\section{MATERIALS AND MeTHODS}

\subsection{Discuss the Methods}

Statistics of the synoptic weather stations at Isfahan and Rasht for the statistical period of 1970-2011 were used. Meteorological information used included minimum and maximum temperatures, minimum and maximum humidity, wind speed, and sunshine hours. The average meteorological parameters and geographical location of the studied areas are presented in Table (1) and Fig. (1).

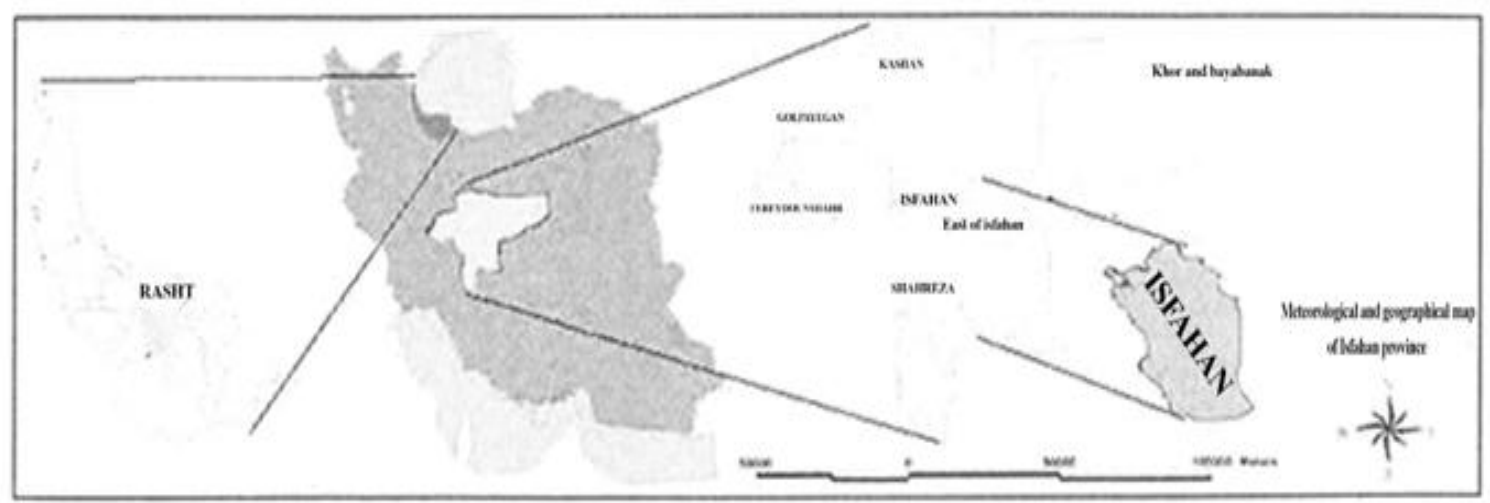

Isfahan, Sep. 2015

Geographical location of the city of Isfahan and Rasht

Table1. Geographic and meteorological parameters of stations for statistical period (1970-2011)

\begin{tabular}{|c|c|c|c|c|c|c|c|c|c|}
\hline $\begin{array}{c}\text { Wind } \\
\text { speed } \\
\text { meter } \\
\text { in } \\
\text { seconds }\end{array}$ & $\begin{array}{c}\text { The } \\
\text { number } \\
\text { of } \\
\text { sunny } \\
\text { hours }\end{array}$ & $\begin{array}{c}\text { Maximu } \\
\mathrm{m} \\
\text { humidity }\end{array}$ & $\begin{array}{c}\text { Minimum } \\
\text { humidity }\end{array}$ & $\begin{array}{c}\text { Maximum } \\
\text { temperature }\end{array}$ & $\begin{array}{c}\text { Minimum } \\
\text { temperature }\end{array}$ & $\begin{array}{c}\text { Above } \\
\text { sea } \\
\text { level }\end{array}$ & $\begin{array}{c}\text { latitud } \\
\mathrm{e}\end{array}$ & $\begin{array}{c}\text { Longitu } \\
\text { de }\end{array}$ & $\begin{array}{c}\text { St } \\
\text { ati } \\
\text { on }\end{array}$ \\
\hline 1.21 & 4.52 & 96.06 & 66.41 & 20.56 & 11.64 & -6.9 & 37.25 & 49.60 & \\
\hline 7.74 & 9.09 & 56.10 & 22.21 & 23.46 & 9.50 & 1550.4 & 32.61 & 51.66 & \\
\hline
\end{tabular}

REF-ET software was used to estimate the radiation parameter. First, using the values of wind speed, number of sunshine hours, minimum and maximum temperatures for Rasht and Isfahan, reference evapotranspiration was calculated. Then, by removing solar radiation and using the methods present in the software for estimating this parameter, evapotranspiration was calculated again and evapotranspiration was compared at each step.

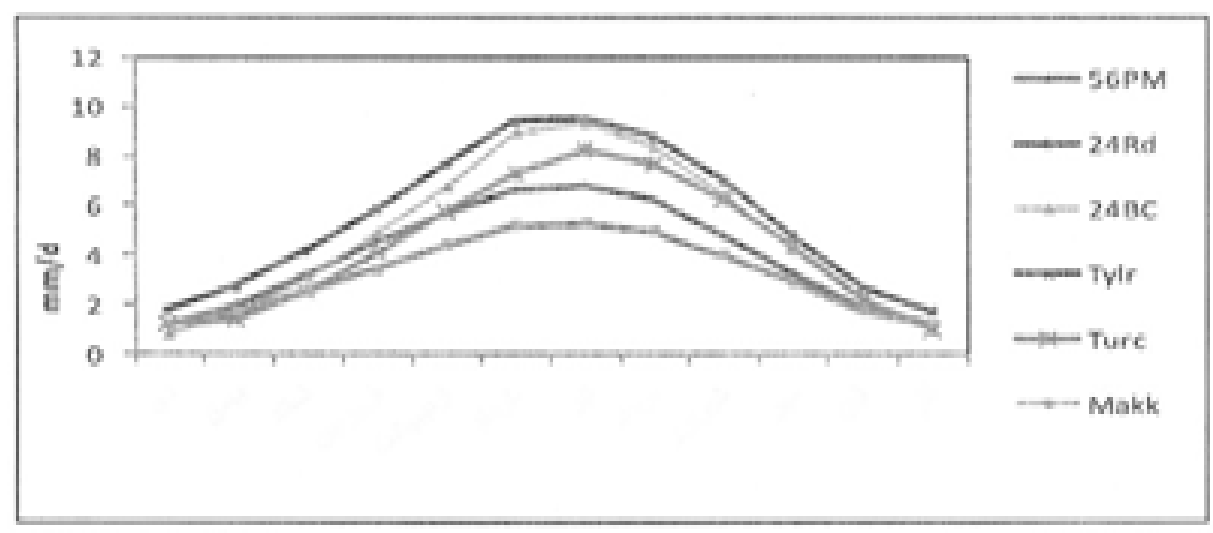




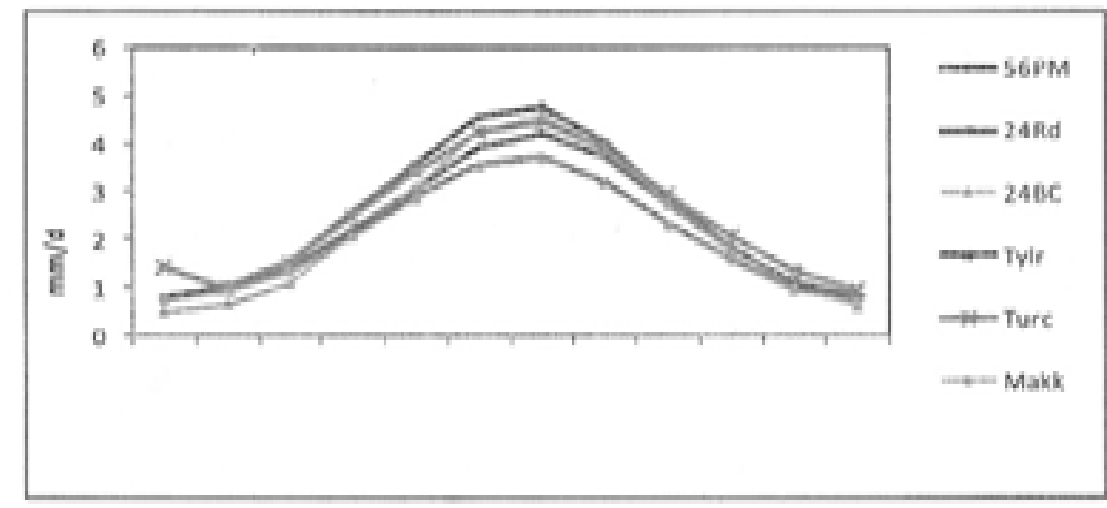

Evapotranspiration chart of reference crop using REF-ET software for Rasht (1970-2011)

Comparison of diagrams show that in the Rasht region differences in the results of equations were negligible and the lines were closer, but in the Isfahan region, these differences were increasing in warm months, but these disparities are negligible in cold months. The three methods used in the software were used to estimate the brightness or radiation parameter. The methods were as follows:

Method 1: This method is influenced by minimum and maximum temperatures. If $\mathrm{Rn}$ is not available, Rs is estimated using equation (1), which is moderated by hermaphrodite variation as proposed by Sarmaniand Hargreaves (1980): $\mathrm{R}_{\mathrm{s}}=\mathrm{K}_{\mathrm{RS}} \times \mathrm{R}_{\mathrm{a}} \times \sqrt{(\text { T max }- \text { Tmin })}$

where $\mathrm{Ra}$ is the outer radiation $\left(\mathrm{MJ} \mathrm{m}^{-2} \mathrm{~d}^{-1}\right)$; $\mathrm{T}(\max )$ is the maximum air temperature (c $\left.{ }^{\prime}\right) ; \mathrm{T}(\mathrm{min})$ is the minimum air temperature (c); and Krs is the correction factor of climate (c). In the first method, the Krs value varied between 0/16 and 0/19, varying in coastal and non-coastal areas. According to the FAO56 model and the publication for non-coastal areas, the correction factor $\mathrm{Krs}$ is 0.16 accordingly, in this study, the values of $0.16,0.17,0.18,0.19$ were considered for the Krs coefficient.

The second method (island): According to $\mathrm{Rs}=0.7 \mathrm{Ra}$, radiation estimated islands can be applied.

Third method (Kg): According to Rs = Kr.Ra, radiation can be estimated by choosing an appropriate value of $\mathrm{Kr}$. the $\mathrm{Kr}$ coefficient was determined based on the climate and region and it was suggested to be between 0-1-1.For the Isfahan region, the coefficient was 0.25 and it was $0.25,0.41,0.61$ for the racetrack. (Proposed by the Authorizing Officers).To compare the relationships, results of the six equations, including Radiation, Blanie-Cradle, Priestly Taylor, McCurve, Torque, and FAO PenmanMonteith, for estimating evapotranspiration were used. These equations are as follows:

\subsection{Fao Penman-Monteith Method}

This method has been introduced by the International Commission on Irrigation and Drainage and the World Food Organization (FAO) as a standard method for calculating potential evapotranspiration. It is assumed that the total surface area of vegetation is a large leaf with its apertures. That is why the Penman-Monteith method is called the (Big Leaf). Its equation is as follows:

$$
\mathrm{ET}_{0}=\frac{0.4 * 8 \Delta\left(R_{n}-G\right)+\gamma\left[\frac{890}{T+273)}\right] U_{2}\left(e_{a}-e_{d}\right)}{\Delta+\gamma\left(1+0.34 u_{2}\right)}
$$

where $\mathrm{Rn}$ is the radiation for the vegetation cover $\left(\mathrm{MJm}^{-2} \mathrm{~d}^{-1}\right)$; $\mathrm{T}$ average air temperature at a height of $2 \mathrm{~m}$ from the ground; $\left({ }^{\circ} \mathrm{C}\right)$; U2 wind speed at 2 meters above the ground $\left(\mathrm{ms}^{-1}\right) ;\left(\mathrm{e}_{\mathrm{a}}-\mathrm{e}_{\mathrm{d}}\right)$ vapor pressure deficiency at 2 meters' height $\left(\mathrm{KPa}^{\circ} \mathrm{c}^{-1}\right) ; \Delta$ curve vapor pressure curve $\left(\mathrm{KPa}^{\circ} \mathrm{c}^{-1}\right) ; \gamma$ moisture factor $\left(\mathrm{KPa}^{\circ} \mathrm{c}^{-1}\right)$; G flame inside the inside soil $\left(\mathrm{MJm}^{-2} \mathrm{~d}^{-1}\right)$.

\subsection{Radiation Method -FAO}

This relationship is presented by Duren bus (1977) as follows:

$\mathrm{ET}_{0}=\mathrm{c}\left[\mathrm{ER}_{\mathrm{s}}+(1-\mathrm{W}) 0.27\left(1+0.01 \mathrm{U}_{2}\right)\left(\mathrm{e}_{\mathrm{a}}-\mathrm{e}_{\mathrm{d}}\right)\right]$

Where $\mathrm{c}$ is the factor that depends on the relative humidity of air and daily wind speed: $\mathrm{w}$ is the weight factor that indicates the effect of temperature in relation to altitude. Rgsolar radiation * wind speed 2 meters above ground level $\left(\mathrm{ms}^{-1}\right)$; and $\left(\mathrm{e}_{\mathrm{a}}-\mathrm{e}_{\mathrm{d}}\right)$ vapor pressure shortage at 2 meters $(\mathrm{mb})$. 


\subsection{Method Blunni-Kerry Dell 1950}

One of the oldest methods for estimating ETO of the grass reference crop, which was investigated at the University of California, is as follows:

$\mathrm{ET}_{0}=\mathrm{a}+\mathrm{b}[\mathrm{p}(0.46 \mathrm{~T}+8.13]$

where $\mathrm{a}$ and $\mathrm{b}$ are climate factors, depending on the relative humidity of the air; actual sunshine, and daily wind speed; $t$ is the average monthly temperature (c); $\mathrm{P}$ is the coefficient of the day or the annual percentage of sunlight in the month, described on a daily basis (average light hours each day per month divided by total light year multiplied by 100).

\subsection{Prestley-Taylor Method 1972}

The Prestley-Taylor method is based on solar radiation and the degree of heat. Its equation is:

$\mathrm{ET}_{0}=1.26 \frac{\Delta}{\Delta+\gamma} \frac{R_{n}-G}{\gamma}$

in which $\mathrm{Rn}$ is radiation; $\mathrm{G}$ flux of heat into the soil $\left(\mathrm{MJm}^{-2} \mathrm{~d}^{-1}\right) ; \lambda$ the heat of evaporation ; $\left(\mathrm{MJkg}^{-1}\right)$; $\Delta$ the slope of the vapor pressure curve $\left(\mathrm{MJkg}^{-1}\right)$; and $\gamma$ is the humidity coefficient $\left(\mathrm{KPa}^{\circ} \mathrm{C}^{-1}\right)$.

\subsection{Macking 1957}

The Macking method is based on solar radiation and temperature. This method was first developed in the Netherlands and then in Australia. In general, it's more applicable to Western Europe, and its equation is as follows:

$\mathrm{ET}_{0}=0.61 \frac{\Delta}{\Delta+\gamma} \frac{R_{S}}{2.45}-0.12$

in which Rsis solar radiation $\left(\mathrm{MJm}^{-2} \mathrm{~d}^{-1}\right)$; $\Delta$ the slope of the steam pressure curve $\left(\mathrm{KPa}^{\circ} \mathrm{C}^{-1}\right) ; \gamma$ the humidity coefficient $2 / 45$; and the latent heat of evaporation at approximately $20^{\circ} \mathrm{C}$. $\left(\mathrm{KPa}^{\circ} \mathrm{C}^{-1}\right)$

\subsection{Torque Method 1961}

The turque method is based on solar radiation and temperature, as in the Macking method. The use of this method was also developed in the Netherlands and then in Australia. Its equation is as follows:

$\mathrm{ET}_{0}=\mathrm{a}_{\mathrm{T}} 0.013 \frac{T_{\text {mean }}}{T_{\text {mean }}+15} \frac{23.8856 R_{S}+50}{\lambda}$

in which Rs of solar radiation $\left(\mathrm{MJm}^{-2} \mathrm{~d}^{-1}\right) ; \mathrm{T}$ is the average temperature of heat $\left({ }^{\circ} \mathrm{C}\right)\left(\frac{T_{\text {mean }}}{T_{\text {mean }}+15}\right)$; and $\lambda$ the latent heat of evaporation $\left(\mathrm{MJkg}^{-1}\right)$. aT the coefficient, when the average daily relative humidity is more than $50 \%$, is considered to be 0.1 , and when the average daily relative humidity is less than $50 \%$, the relation is:

$\mathrm{a}_{\mathrm{T}}=1+\frac{50-R H_{\text {mean }}}{70}$

where relative humidity is in percent. The torque $\mathrm{B}$ equation will only apply when Tmean $>-10^{\circ} \mathrm{C}$. In this study, we used the tests proposed by Jacquids (1997) to evaluate the accuracy of models and compare the results of estimated methods with measured radiation values; wind speed and relative humidity. Jacques showed that the use of RMSE, MBE, MAE alone causing an error in choosing the best model. Therefore, it is recommended that along with these two indicators, the criterion $\mathrm{T}$, which is a combination of them, is also used. These indicators are as follows:

$$
\begin{aligned}
& \text { RMSE }=\sqrt{\frac{\sum_{1}^{n}\left(p_{i}-o_{i}\right)^{2}}{M^{2}}} \\
& \mathrm{MBE}=\frac{\sum_{1}^{n}\left(p_{i}-o_{i}\right)}{n} \\
& \mathrm{MAE}=\sum_{1=1}^{n} A B S\left(p_{i}-o_{1}\right) / n \\
& \mathrm{t}=\sqrt{\frac{(n-1) M B E^{2}}{R M S_{E^{2}}-M B E^{2}}}
\end{aligned}
$$


Evaluation of Radiation Methods for Calculating the Water Requirement of Grass in Two Different Climates Using REF-ET software

These equations are the estimated values of the parameters; Oi is the measured value of the parameter, and $\mathrm{n}$ is the number of observations. Results of this test for the radiation parameter for two regions of Isfahan and Rasht are presented in Tables 2 and 3, respectively. Comparison of results indicates that if the radiation parameter is not available for Isfahan, the first method with coefficient $\mathrm{Krs}=0.17$ and for the Rasht method using the third method with coefficient $\mathrm{Krs}=0.44$ will produce results closer to reality. Also, for the Isfahan region, results of the Torque equation and for Rasht equal the results of the Penman-Monteith equation, as well as other empirical equations. For Isfahan, results of the Penman-Monteith-FAO and Torque equation had little difference in comparison with other equations.

Evapotranspiration of reference crop using REF-ET software in Isfahan city

\begin{tabular}{|c|c|c|c|c|c|c|c|}
\hline $\mathrm{T}$ & RSME & MBE & MAE & Equation & Value & Method & Parameter \\
\hline 5.61 & 0.11 & 0.08 & 0.08 & PM65 & & & \\
\hline 6.87 & 0.35 & 0.28 & 0.28 & $\mathrm{Rd} 42$ & \multirow{5}{*}{$\mathrm{KRS}=6 \mathrm{v} 5$} & \multirow{23}{*}{ ONE } & \\
\hline 6.16 & 0.22 & 0.17 & 0.17 & BC42 & & & \\
\hline 5.79 & 0.15 & 0.11 & 0.11 & Tylr & & & \\
\hline 7.27 & 0.20 & .16 & 0.16 & Makk & & & \\
\hline 6.30 & 0.26 & 0.20 & 0.20 & Turc & & & \\
\hline 2.21 & 0.04 & -0.02 & 0.03 & PM65 & \multirow{6}{*}{$\mathrm{KRS}=6 \mathrm{v} 0$} & & \\
\hline 2.62 & 0.14 & -0.07 & 0.10 & $\mathrm{Rd} 42$ & & & \\
\hline 2.49 & 0.08 & -0.04 & 0.05 & BC42 & & & \\
\hline 2.22 & 0.06 & -0.03 & 0.04 & Tylr & & & \\
\hline 2.76 & 0.08 & -0.04 & 0.06 & Makk & & & \\
\hline 2.18 & 0.09 & -0.04 & 0.06 & Turc & & & \\
\hline 7.77 & 0.14 & -0.12 & 0.12 & PM65 & \multirow{6}{*}{$\mathrm{KRS}=6 \mathrm{v} 0$} & & \\
\hline 8.74 & 0.46 & -0.41 & 0.41 & $\mathrm{Rd} 42$ & & & \\
\hline 8.48 & 0.28 & -0.24 & 0.24 & BC42 & & & \\
\hline 7.45 & 0.20 & -0.17 & 0.17 & Tylr & & & \\
\hline 9.18 & 0.27 & -0.24 & 0.24 & Makk & & & \\
\hline 8.42 & 0.31 & -0.28 & 0.28 & Turc & & & \\
\hline 7.75 & 0.26 & -0.22 & 0.22 & PM65 & \multirow{6}{*}{$\mathrm{KRS}=6 \mathrm{v} 0$} & & \\
\hline 8.53 & 0.84 & -0.76 & 0.76 & $\mathrm{Rd} 42$ & & & \\
\hline 8.25 & 0.49 & -0.43 & 0.43 & BC42 & & & \\
\hline 7.63 & .37 & -0.31 & 0.31 & Tylr & & & \\
\hline 9.19 & 0.48 & -0.44 & 0.44 & Makk & & & \\
\hline 8.23 & $0.58 /$ & -0.51 & 0.51 & Turc & & & \\
\hline 5.84 & 0.20 & 0.15 & 0.15 & PM65 & \multirow{6}{*}{$\mathrm{R}_{\mathrm{a}}=4$} & \multirow{6}{*}{ TWO } & \\
\hline 6.88 & 0.70 & 0.57 & 0.59 & $\mathrm{Rd} 42$ & & & \\
\hline 6.39 & 0.44 & 0.34 & 0.35 & BC42 & & & \\
\hline 5.98 & 0.28 & 0.21 & 0.22 & Tylr & & & \\
\hline 7.38 & 0.40 & 0.33 & 0.34 & Makk & & & \\
\hline 6.29 & 0.53 & 0.40 & 0.41 & Turc & & & \\
\hline 6.32 & 1.23 & 1.01 & 1.01 & PM65 & \multirow{6}{*}{$\begin{array}{c}\mathrm{KRS}=614 \\
6\end{array}$} & \multirow{6}{*}{ THREE } & \\
\hline-3.84 & 3.98 & 3.55 & 3.55 & $\mathrm{Rd} 42$ & & & \\
\hline 3.02 & 2.61 & 2.21 & 2.21 & BC42 & & & \\
\hline 5.39 & 1.74 & 1.43 & 1.43 & Tylr & & & \\
\hline 4.83 & 2.26 & 2.05 & 2.05 & Makk & & & \\
\hline 1.96 & 2.88 & 2.44 & 2.44 & Turc & & & \\
\hline
\end{tabular}

Evapotranspiration chart of reference plant using software REF-ET in Rasht (1970-2011)

\begin{tabular}{|c|c|c|c|c|c|c|c|}
\hline $\mathrm{T}$ & RSME & $\mathrm{MBE}$ & MAE & Equation & Value & Method & Parameter \\
\hline 0.30 & 0.20 & 0.10 & 0.10 & PM65 & & & \\
\hline 6.14 & 0.28 & -0.21 & 0.23 & $\mathrm{Rd} 42$ & & \multirow[t]{7}{*}{ ONE } & \\
\hline 5.79 & 0.14 & -0.10 & 0.12 & BC42 & & & \\
\hline 4.33 & 0.19 & -0.12 & 0.14 & 4.33 & & & \\
\hline 6.22 & 0.22 & -0.16 & 0.18 & Makk & & & \\
\hline 6.23 & 0.21 & -0.16 & 0.18 & Turc & & & \\
\hline 7.29 & 0.22 & -0.18 & 0.18 & PM65 & \multirow[t]{2}{*}{$\mathrm{KRS}=6 \mathrm{v} 0$} & & \\
\hline 8.90 & 0.44 & -0.40 & 0.40 & Rd42 & & & \\
\hline
\end{tabular}


Evaluation of Radiation Methods for Calculating the Water Requirement of Grass in Two Different Climates Using REF-ET software

\begin{tabular}{|c|c|c|c|c|c|c|}
\hline 8.99 & 0.22 & -0.20 & 0.20 & BC42 & & \\
\hline 7.20 & 0.30 & -0.25 & 0.25 & Tylr & & \\
\hline 9.01 & 0.34 & -0.31 & 0.31 & Makk & & \\
\hline 9.00 & 0.34 & 0.21 & 0.31 & Turc & & \\
\hline 7.75 & 0.32 & -0.27 & 0.27 & PM65 & \multirow[t]{6}{*}{$\mathrm{KRS}=6 \mathrm{v} 0$} & \\
\hline 9.31 & 0.62 & -0.58 & 0.58 & $\mathrm{Rd} 42$ & & \\
\hline 9.29 & 0.22 & -0.30 & 0.30 & $\mathrm{BC} 42$ & & \\
\hline 7.60 & 0.45 & -0.28 & 0.28 & Tylr & & \\
\hline 9.50 & 0.48 & -0.45 & 0.45 & Makk & & \\
\hline 9.41 & 0.48 & -0.45 & 0.45 & Turc & & \\
\hline 7.60 & 0.44 & -0.37 & 0.37 & PM65 & \multirow[t]{6}{*}{$\mathrm{KRS}=6 \mathrm{v} 0$} & \\
\hline 9.17 & 0.82 & -0.77 & 0.77 & $\mathrm{Rd} 42$ & & \\
\hline 9.13 & 0.43 & -0.39 & 0.39 & BC42 & & \\
\hline 7.50 & 0.60 & -0.51 & 0.51 & Tylr & & \\
\hline 9.45 & 0.63 & -0.59 & 0.59 & Makk & & \\
\hline 9.31 & 0.64 & -0.60 & 0.60 & Turc & & \\
\hline 7.05 & 0.48 & -0.39 & 0.39 & PM65 & \multirow[t]{6}{*}{$\mathrm{R}_{\mathrm{a}}=4$} & \multirow[t]{6}{*}{ TWO } \\
\hline 7.75 & 0.85 & -0.74 & 0.74 & $\mathrm{Rd} 42$ & & \\
\hline 7.81 & 0.45 & -0.29 & 0.29 & BC42 & & \\
\hline 6.90 & 0.66 & -0.53 & 0.53 & Tylr & & \\
\hline 8.02 & 0.65 & -0.57 & 0.57 & Makk & & \\
\hline 7.85 & 0.66 & -0.75 & 0.57 & Turc & & \\
\hline 5.69 & 0.87 & 0.65 & 0.65 & PM65 & \multirow[t]{6}{*}{$\mathrm{KR}=6146$} & \multirow[t]{6}{*}{ THREE } \\
\hline 6.43 & 1.44 & 1.22 & 1.22 & $\mathrm{Rd} 42$ & & \\
\hline 6.65 & 0.84 & 0.68 & 0.68 & BC42 & & \\
\hline 5.42 & 1.18 & 0.89 & 0.89 & Tylr & & \\
\hline 7.14 & 1.10 & 0.94 & 0.94 & Makk & & \\
\hline 6.83 & 1.15 & 0.97 & 0.97 & Turc & & \\
\hline 0.39 & 0.16 & 0.03 & 0.11 & PM65 & \multirow[t]{6}{*}{$\mathrm{KR}=6122$} & \multirow[t]{6}{*}{ FOUR } \\
\hline 0.01 & 0.28 & -0.01 & 0.22 & $\mathrm{Rd} 42$ & & \\
\hline 0.09 & 0.015 & 0.01 & 0.12 & BC42 & & \\
\hline 0.33 & 0.21 & 0.04 & 0.15 & Tylr & & \\
\hline 0.02 & 0.21 & -0.01 & 0.17 & Makk & & \\
\hline 0.00 & 0.21 & 0.00 & 0.17 & Turc & & \\
\hline 7.43 & 0.74 & -0.62 & 0.62 & PM65 & \multirow[t]{6}{*}{$\mathrm{KR}=6155$} & \multirow[t]{6}{*}{ FIVE } \\
\hline 8.32 & 1.36 & -1.30 & 1.30 & $\mathrm{Rd} 42$ & & \\
\hline 8.87 & 0.72 & -0.66 & 0.66 & $\mathrm{BC} 42$ & & \\
\hline 7.13 & 1.01 & -0.86 & 0.86 & Tylr & & \\
\hline 9.05 & 1.05 & -1.00 & 1.00 & Makk & & \\
\hline 8.87 & 1.07 & -1.01 & 1.01 & Turc & & \\
\hline
\end{tabular}

Comparison of results showed that if there was no radiation parameter, using the third method $(\mathrm{Kg})$ and assuming $\mathrm{Kr}=0.44$, the best estimate would be for Rasht area. Because RMSE and T coefficient, which is a composite index, are less for the studied methods; this indicates a high accuracy in the estimation of parameters.

\section{CONCLUSION}

This study showed that in the region of Rasht for the radiation parameter, the third method (Krs) has the best estimate if $\mathrm{Kr}=0.41$. For the Isfahan region, for the radiation parameter, the third method (Krs) has the best estimate if the value of $\mathrm{Kr}=0.44$. For the Isfahan region, for the radiation parameter; in the first method (the difference between minimum and maximum temperature), if $\mathrm{Krs}=$ 0/17, the result is better. Results also showed that the evapotranspiration values obtained from the Penman-Monteith relation for Rasht and the evapotranspiration values obtained from the Turque relation for Isfahan with the reconstruction of the radiation parameter are closer to the evapotranspiration obtained from measured parameters. With the reconstruction of the radiation parameter for Isfahan, results of the Penman-Monteith-FAO and Torque equations are slightly different from those of other equations. 


\section{REFERENCES}

[1] Ansari, H, and Moradi; (H) (2010) A Fuzzy Model for Estimating Hourly Reference Evapotranspiration using Minimum Meteorological Data; Journal of Water and Soil; No. 2. Page 286-275

[2] Erfanian; and Baba'i; (2013). Estimation of hybrid model in solar radiation estimation and preparation of seasonal maps of radiation for Urmia lake; 5th international congress of geographers of Islamic world; Tabriz.

Citation: Masoumeh Najafi, et.al. "Evaluation of Radiation Methods for Calculating the Water Requirement of Grass in Two Different Climates Using REF-ET software", International Journal of Constructive Research in Civil Engineering, 5(1), pp. 1-7. DOI: http://dx.doi.org/10.20431/2454-8693. 0501001

Copyright: () 2018 Authors, This is an open-access article distributed under the terms of the Creative Commons Attribution License, which permits unrestricted use, distribution, and reproduction in any medium, provided the original author and source are credited. 